\title{
O CUIDAR EM UNIDADES DE CUIDADOSINTENSIVOS NEONATAIS: EM BUSCA DE UM CUIDADO ÉTICO E HUMANIZADO
}

[C are in neonatal intensive care units: searching for an ethical and humanized care] [El cuidar en unidades de cuidados intensivos neonatales: en busca de un cuidado ético y humanizado]

RESUM O: Este artigo propõe uma reflexão sobre o cuidado ao recém-nascido internado em U nidade de Cuidado Intensivo N eonatal (UCIN), a partir da análise dos ef eitos dos avanços tecnológicos e das relações bioéticas envolvidas no processo de cuidar do neonato. A rgumenta-se em prol da re-organização do processo de trabalho na assistência neonatal, da valorização da dimensão subjetiva no cuidado, do respeito à autonomia dos familiares e da incorporação de outros instrumentais de trabal ho como a sensibilidade, o diálogo e a solidariedade humana.

PALAVRAS-CHAVE: Prestação de cuidados de saúde; Bioética; Cuidados intensivos; Enfermagem neonatal.

ABSTRACT: The present article proposes a discussion about the newborn care delivered in intensive care units (ICUS), through the analysis of the effects of technological breakthroughs and bioethical relations involved with the new born care process. It is claimed the reorganization of the work process in newborn care delivery, the value of the subjective care dimension, the respect to the family autonomy and the incorporation of other work instruments such as sensitivity, dialogue and human solidarity.

KEYWORDS: Delivery of health care; Intensive care; Bioethics; N ewborn nursing.

RESUMEN: Este artículo propone una reflexión acerca del cuidado del recién nacido internado en Unidade de Cuidado Intensivo Neonatal (UCIN), por medio del análisis de los efectos de los avances tecnológicos y las relaciones bioéticas que están en el proceso de cuidar del neonato. Se argumenta a favor de la reorganización del proceso de trabajo en la asistencia neonatal, la valorización de la dimensión subjetiva en el cuidado, el respecto a autonomía de los familiares y la incorporación de otros instrumentales de trabajo, como la sensibilidad, el diálogo y la solidaridad humana.

PALABRAS CLAVE: Prestación de atención de salud; Bioetica; Cuidados intensivos; Enfermería neonatal. *Enfermeira. Professora doutora do Departamento de Enfermagem da Faculdade de Enfermagem da Universidade Federal de M ato Grosso.
M embro do Grupo de Pesquisa A rgo. 


\section{INTRODUÇÃO}

$\mathrm{N}$ as últimas décadas as inovações tecnológicas no campo das ciências médicas e biológicas resultaram em importantes benefícios para o ser humano com melhoria das condições dos cuidados de saúde. A utilização de tecnologias materiais nas U nidades de Cuidados Intensivos $\mathrm{N}$ eonatais (UCINs) tem levado à progressiva melhora do atendimento e decréscimo da mortalidade neonatal, principalmente dos bebês de muito baixo peso.

A tecnologia enquanto objeto material, instrumental derivado do conhecimento científico e utilizado para a transformação intencional de uma real idade concreta, pode ser considerada elemento de fundamental importância para a mel horia das condições de assistência à saúde. A partir da década de 60 do século passado, no campo da neonatologia, a tecnologia foi a responsável pelos grandes avanços na assistência aos recém-nascidos prematuros e de al to risco. Paral el amente, houve uma maior incidência de iatrogênias, gerando preocupações com as questões éticas e morais na assistência ao neonato.

M esmo conhecendo as inúmeras contribuições da tecnol ogia na área da saúde, no que diz respei to à utilização de equipamentos diagnósticos e terapêuticos, não podemos deixar de apontar que o uso de tecnologias, apesar de todas as conquistas, tem merecido críticas. M uitas delas fazem um contraponto com a humanização da assistência, principalmente no que diz respeito às relações entre os profissionais e os objetos/artefatos com os quais trabal ham. A lém do mais, al guns críticos al egam que muitas tecnologias usadas na neonatologia não foram testadas através de estudos controlados na clientela neonatal, são adaptações de tecnologias usadas em adultos.

A tecnologia trouxe e continua trazendo benefícios para a assistência à saúde. M as trouxe também algumas conseqüências que podemos considerar danosas e que têm reflexos diretos no processo de cuidar na área neonatal. 0 avanço tecnológico nos põe frente-a-frente com vários dilemas éticos no dia-a-dia e impõe a necessidade de reconsideração destes avanços não somente quanto aos aspectos técnicos e biológicos. Neste sentido, os profissionais de saúde envolvidos na assistência neonatal têm demonstrado preocupação e investido na construção de uma nova qual idade assistencial. Comprometidos com essa construção, temos aprofundado os estudos sobre a temática, no sentido de responder as necessidades de saúde do neonato e família, contribuindo com a melhoria da qual idade da assistência prestada nas U CIN s.

A ssim, este artigo objetiva discutir, numa perspectiva teórico-reflexiva, o cuidado ao recém-nascido internado em U CIN , analisando os efeitos dos avanços tecnológicos e as relações bioéticas envolvidas no processo de cuidar. Para subsidiar essa proposta nos apoiamos em formulações da literatura atual e de nossa experiência profissional como enfermeira que atua a quase duas décadas em unidade de internação neonatal.

\section{O CUIDADO EM UCIN NEONATAL: OSAVANÇOS TECNOLÓGICOSE A QUESTÃO ÉTICA}

A crescente complexidade e avanços da assistência neonatal nos úl timos anos e a necessi dade de se buscar uma assistência humanizada impõem a necessidade de refletirmos acerca das questões bioéticas no cotidiano das unidades neonatais. Cabe lembrar que o objetivo da bioética é a busca de benefício e da garantia da integridade do ser humano, tendo como fio condutor o princípio básico de proteção à dignidade humana.

A o cuidarmos do ser humano devemos considerar os quatro princípios fundamentais da bioética para nortear nossas ações: beneficência, não mal eficência, autonomia e justiça. A beneficência refere-se a obrigação ética de maximizar benefícios e minimizar danos ou prejuízos, ou seja, salvaguardar o bem-estar dos sujeitos ${ }^{(1)}$. A nãomal eficência significa não causar danos ou prejuízos, envolve abstenção e é assegurada a todas as pessoas, sendo a primeira e grande norma de conduta dos profissionais da área da saúde. A autonomia refere-se ao grau de poder da pessoa de tomar decisões que afetam sua vida, sua integridade e suas relações sociais. De forma sintética, podemos dizer que 0 respeito pela pessoa deve atender/ primar pelo respeito à sua autonomia em deliberar sobre suas escol has. E aquelas pessoas com autonomia diminuída (dependentes/vulneráveis) devem ser protegidas contra danos ou abusos.

A autonomia do sujeito éum dos pontos básicos que fundamenta toda e qualquer relação entre seres humanos. No caso específico da criança há uma violação consciente e aceita socialmente da autonomia(2). Esse é o comportamento esperado numa sociedade, espera-se que, no caso da criança/recém-nascido, a mãe o "proteja" e, portanto, decida por ele enquanto el e necessitar.

0 princípio da autonomia de certa forma é visto com ressal vas quando se refere a área neonatal. A final, quem é que determina a escolha do que é o melhor ou mais apropriado ao recém-nascido hospitalizado, os profissionais ou seus pais? Considerando que a autonomia éo direito de uma pessoa tomar suas próprias decisões e que os bebês não são capazes de expressar autonomia, são os pais legalmente autorizados a dar consentimento para que um tratamento seja feito.

A lguns profissionais questionam se real mente os pais estariam preparados para decidir, estarão eles a defender seus reais interesses ou os interesses do recém-nascido? Essa é uma questão muito complexa e que cada situação merece uma análise específica. Portanto, não há como impor regras. $\mathrm{Na}$ verdade, não há uma única resposta ou solução para essa questão, o que deve existir é a construção conjunta de discussões em cada momento, amadurecidas a partir de muito diálogo entre pais e profissionais e que, ao final, de fato respeite a autonomia do bebê.

Em muitas situações, no cotidiano dos serviços 
neonatais, o uso da tecnologia impede que os familiares manifestem sua autonomia, seja porque não Ihes é dada a oportuni dade ou por fal ta de informação ou esclarecimento. Considera-se que o sujeito precisa ter resguardado seu direito/liberdade de concordar ou não com determinadas situações. Face ao domínio psicológico, conhecimentos e habilidades técnicas que possuem, os profissionais podem inviabilizar a real manifestação da vontade dos pais, ferindo dessa forma o princípio da autonomia individual. Destacamos aqui a importância do consentimento esclarecido, elemento que deve ser respeitado, mesmo em se tratando da assistência ao bebê, consi derado um ser não autônomo. Entretanto, sabemos que em situação de cuidados intensivos esse é um princípio nem sempre respeitado, a família somente é consultada em situações muito específicas ou extremas.

Para tal, deve-se buscar ao máximo o envolvimento dos pais, oferecendo-Ihes todas as informações disponíveis para prepará-los para a tomada de decisão. A própria equipe deve estar preparada, ser sensível ao diálogo e ter claro que em determinados momentos não há opinião de consenso, mas que el e deve ser buscado, independentemente do tempo e dos esforços.

A I guns autores ${ }^{(3,4)}$ reforçam este aspecto ao discutir as questões éticas nas unidades de cuidados neonatais, al ertando que quando se trata de anal isar os benefícios dos procedimentos a serem executados é indispensável garantir o direito à informação e ouvir a opinião dos pais, buscando o desenvolvimento de um trabalho conjunto entre profissionais e familiares.

A pesar de estar incorporada na medicina desde seus primórdios, a discussão sobrea autonomia na neonatologia ainda pode ser considerada uma questão muito recente em nosso meio. Pode-se dizer que ela surge em meio aos debates acerca da bioética. Os profissionais que atuam em U CINs, em sua mai oria, são contrários à partici pação da família na tomada de decisão ${ }^{(4)}$. Em al guns países, o questionamento ético acerca da autonomia dos familiares ainda está no âmbito da equipe/profissionais.

A busca pelo respeito à autonomia do recém-nascido como ser humano, deve ser uma luta de todos os membros da equipe e principalmente dos familiares, que atual mente estão mais presentes e ativos dentro das U CIN e participam do cotidiano do assistir em muitos de nossos serviços.

A reflexão acerca das tecnologias em ambientes neonatais nos remete necessariamente aos princípios éticos de justiça, equidade e não-discriminação dos indivíduos no uso das tecnologias. 0 princípio da justiça é muito amplo e entre os diversos critérios para o respeito a esse princípio, está o tratar as pessoas de acordo com suas necessidades e/ ou capacidades.

$\mathrm{N}$ a área neonatal essa é uma preocupação que deve estar muito presente em nosso meio, uma vez que no Sistema Ú nico de Saúde a demanda por leitos neonatais é grande e
- acesso é restrito, dada a escassez numérica de equipamentos e leitos disponíveis, o que pode ampliar as desigualdades existentes no sistema de saúde e ferir 0 princípio da justiça que pressupõe acesso igualitário e um atendimento de qualidade.

A defesa da dignidade humana nos reporta a um de seus pilares que é a não maleficência, muitas vezes ignorada nas UCNs, em que os prematuros ou bebês gravemente doentes são freqüentemente expostos a riscos de iatrogênias, além de situações de desconforto, estresse e estímulos dolorosos, seja através dos procedimentos diagnósticos ou de medidas terapêuticas, muitas vezes realizadas sem uma cuidadosa avaliação dos riscos e benefícios.

A dor se faz presente no cotidiano da assistência ao bebê de risco, embora na maioria das vezes ela seja ignorada ou encarada sem a atenção devida e, apesar de existirem tecnologias para a prevenção ou tratamento, nem sempre elas são empregadas na assi stência a essas crianças. Se considerarmos que o neonato é um sujeito e, como tal, possuidor de direitos, dentre os quais o " direito a não sentir dor, quando existam meios para evitá-la" , conforme consta no item 7 da Resolução dos Direitos da Criança e do A dolescente Hospitalizados ${ }^{(5)}$, verifica-se a clara violação desse direito em muitas situações em nossas UCINs.

A tual mente, muito se pode fazer para evitar a dor e o sofrimento desnecessário dos neonatos hospitalizados, pois além da terapêutica medicamentosa, a equipe, principalmente a de enfermagem, pode valer-se de outras medidas alternativas de alívio efetivo do desconforto e da dor.

Outro aspecto que merece ser destacado nesta discussão são os efeitos que a biotecnologia tem no relacionamento da equipe e recém-nascido. 0 enfoque centrado no corpo humano como uma máquina desloca 0 olhar dos profissionais para partes cada vez menores do corpo, reduzindo a saúde como mero funcionamento mecânico do corpo. Negligenciando-se outros aspectos envolvidos no processo de assistir, perdendo de vista a perspectiva integral ao ol har o ser humano em partes e não holisticamente, pouco sustentadas em um vínculo ético-afetivo.

A medicina tecnocientífica presente hoje na assistência ao neonato tem enfrentado novos dilemas que os códigos de éticas profissionais sozinhos não dão conta de responder. É nesse contexto que a bioética, vista como uma nova configuração ética, baseada em valores contextualizados, pode nos ajudar a responder aos questionamentos enfrentados no cotidiano das U CIN s.

Dessa forma, os princípios éticos devem servir de base para que os profissionais atuantes em U CIN s possam refletir sobre seus comportamentos e principalmente na tomada de decisão no momento de assistir ao recémnascido e família. 


\subsection{A BUSCA POR UM CUIDADO MAIS HUMANO E ÉTICO}

A s novas concepções filosóficas e a falência do modelo biologista têm propiciado o repensar das práticas de cuidar, dando a estas uma visão humanista e existencial do ser cuidado ${ }^{(6)}$. N esse sentido, no B rasil já existem al guns programas propostos pelo Estado para a humanização das ações em saúde nível hospitalar. 0 primeiro deles é 0 Programa de Humanização no Pré-Natal e Nascimento, criado através da Portaria 560/GM de 01/06/2000, que preconiza que os serviços de saúde são responsáveis pela garantia dos direitos das gestantes e recém-nascidos, de forma humanizada e segura ${ }^{(7)}$. O utro projeto é o Programa Nacional de Humanização da Assistência Hospitalar (PNHAH), lançado em 19/06/2001 pelo Ministério da Saúde, através da Portaria G M /M S no $881^{(8)}$.

0 PNHAH é uma política ministerial singular se comparada a outras do setor saúde, para promover uma nova cul tura de assistência à saúde no país. A proposta tem como objetivo fundamental aprimorar as relações entre profissionais, entre usuários/profissionais e entre hospital e comunidade, visando à mel horia da qualidade dos serviços prestados ${ }^{(8)}$

A pesar da assistência ao prematuro em unidades neonatais ter passado por importantes transformações, seja em virtude das inovações tecnológicas, seja na perspectiva da inserção da família e humanização do cuidado, constatamos que muitas UCINs ainda expressam em seu cotidiano as imagens de um trabalho marcado pela apropriação do corpo débil do prematuro, não respeitando as peculiaridades de cada bebê e seu desenvolvimento integral, mas exaltando as tendências de um trabalho tecnificado e rotinizado que caracteriza o modelo biologicista de cuidar ${ }^{(9)}$.

Em 1995 foi publicado, através do Ministério da Justiça e Consel ho Nacional dos Direitos da Criança e do A dolescente, "Os Direitos da Criança e do A dolescente Hospitalizado (5)", aprovando na íntegra. 0 texto oriundo da Sociedade B rasileira de Pediatria.

Passada mais de uma década, a grande maioria dos profissionais que trabalha diretamente com a criança hospitalizada desconhece tal diploma de direitos. Por desconhecimento, ou não, observamos no cotidiano da assistência ao recém-nascido, a transgressão a muitos desses direitos, conduzindo a situações de dor e sofrimento desnecessários.

A assistência neonatal não deve se limitar a evitar a al ta mortalidade de seres naturalmente frágeis e sujeitos a tantos riscos, mas deve se preocupar com as repercussões tardias dos problemas perinatais nos sobreviventes, assumindo atitudes não só curativas, mas abrangendo os aspectos físi cos e psicossociais, na perspectiva da promoção da saúde e da qualidade de vida.
Com a introdução ampla e intensa de equipamentos, instrumentos, utensílios/artefatos, etc., entre o cuidador e 0 ser que é cuidado, ampli ou-se a distância entre esses suj ei tos, especialmente na clínica, que cuida do indivíduo. Na mesma dimensão, a distância entre o(s) cuidador(es) e o sujeito coletivo amplia-se permanentemente, pois a noção de cuidado, neste caso, adotou um caráter de intervenção, denotando, assim, uma idéia impositiva, de objetificação sobre quem necessita daquele cuidado ${ }^{(10)}$.

Cuidar não é somente assistir, que tem um sentido confinado ao ato de olhar, de ver, de expectar, muitas vezes sem perceber, sem entender porque não interpretou o que assistiu, o que viu. A UCIN, por ser um local em que há concentração de pacientes graves e situações de contínuas emergências, contribui para comportamentos automatizados, nos quais o diálogo e a reflexão crítica não encontram espaço, tornando o cuidado mecanizado, desprovido de sentimento, dotado apenas de um caráter de "exercício de" fazer uma assistência. M ais um saber-fazer que se objetiva numa ação e não numa atitude, que incorpora a idéia de comportamento.

Pensar o cuidado nos remete à questão da humanização da assistência à saúde, que é uma demanda atual e crescente no contexto brasileiro. Essa humanização pode ser vista sob um prisma multidimensional, requerendo, portanto, atenção a inúmeros aspectos, dentre el es o cuidar.

No contexto da assistência ao neonato algumas intervenções têm sido recomendadas e implementadas nas unidades neonatais para instrumentalizar o trabalho da equipe de saúde e prestar uma assistência integral e humanizada, tais como: a liberação de visitas de outros membros da família, a permanência dos pais junto ao filho internado, a implementação de grupos de apoio aos familiares, o incentivo à participação da mãe no cuidado ao bebê e na tomada de decisão do tratamento. N essas ações, evidencia-se a tentativa de ultrapassar o model o centrado no corpo doente do neonato, mediante a organização da assistência tendo como o foco o bebê e a família.

Buscar formas efetivas para tornar o cuidado mais humano e ético implica aproximação crítica que possibilite compreender a temática além de seus componentes técnicos, instrumentais, envolvendo, principalmente, as suas dimensões político-filosóficas que Ihe imprimem um sentido (11).

A o considerarmos que o cuidador/profissional é o elemento fundamental para um cuidado humanizado, aspectos relacionados à atitude profissional, principal mente os mais subjetivos merecem destaque.

Neste sentido, as práticas dos profissionais adquirem ganhos qual itativos quando as ações de cuidado são dotadas de intencionalidade; do contrário, o cuidado torna-se vazio e sem sentido, perdendo a razão de ser do ponto de vista da subjetividade. Quando o profissional adota essa postura no decorrer do processo de cuidar, o receptor do cuidado (cliente) sente/vivencia o processo de forma plena, tem a sensação de ser atendido em suas necessidades e não como 
um mero objeto/coisificado (10).

Para tal, o profissional deve desenvolver e aplicar não somente as habilidades e saberes técnicos, mas também as habilidades sensíveis do relacionamento interpessoal fundado na dialogicidade. Entendemos que o diálogo pode ser visto como uma ferramenta para um cuidado mais humano e ético, pois a comunicação e a interação com 0 outro podem gerar novas possibilidades de enfrentamento de uma situação de dificul dade pelo cliente. A comunicação seja ela verbal ou não verbal, implica em saber ouvir, sensibilidade em quando e o que falar, quando tocar, compartilhar idéias e decisões. 0 que, uma vez mais, traduz a idéia de que o cuidado pressupõe uma relação pessoa a pessoa e não a individualidade.

No trabalho em UCINs, o enfermeiro necessita utilizar os equipamentos de alta complexidade aliados a outros instrumentos de trabal ho como a experiência, a compreensão do cuidado que presta, a sensibilidade e 0 relacionamento interpessoal terapêutico, a fim de prover um cuidado seguro, responsável e ético em uma realidade vivencial na qual se depara, freqüentemente, com a instabilidade do estado clínico do bebê e com a ansiedade da família.

A ef etivação de uma atenção humanizada exige dos profissionais não somente a competência técnica, mas a vivencia ética. Nesse sentido o ensino da bioética pode fornecer instrumentos, novos olhares, tornar inteligíveis determinadas situações, contribuindo para que o profissional tenha um ol har diferente daquel e que a pratica Ihe impõe.

A inda, é preciso ter claro que a qualificação e 0 aprimoramento dos membros da equipe são cada vez mais necessários, para que possam acompanhar as mudanças no âmbito da saúde. Ressaltamos aqui a necessidade de que a capacitação dos profissionais compreenda também os valores éticos.

0 cuidado humano não deve ser tratado como uma intervenção sobre o paciente. A relação não é sujeito-objeto, mas sujeito-sujeito. Logo, a relação do cuidado não é de domínio sobre, mas de convivência, não é pura intervenção e sim entrar em sintonia com ${ }^{(12)}$.

$\mathrm{Na}$ maioria das nossas $\mathrm{U} C \mathrm{CIN}$ s, assim como em outras unidades do hospital, os cuidados são realizados de forma planejada, sem levar em conta as necessidades do sujeito, o que é chamado por al guns como o cuidado burocrático. M esmo que o cuidador tenha toda uma preocupação em não causar prejuízo e mal estar a quem se cuida, o cuidado é sempre realizado a partir do ponto de vista do cuidador. Sabemos que o cuidado ideal é aquele que para ser desenvolvido necessita de uma observação prévia, análise da real necessidade do procedimento e que é feito no momento mais adequado ao paciente.

A forma de organizar o processo de trabalho centralizado em normas e rotinas, com horários rígidos, pouco favorece o cuidado integral/humanizado. A busca pela humanização da assistência em U CIN s impõe a organização do trabal ho de forma a permitir uma assistência voltada para as necessidades individualizadas dos bebês, na qual os cuidados não venham a causar danos na vida futura dessas crianças. A ssim é que diversos autores têm recomendado intervenções para minimizar as fontes de superestimulação e favorecer a adaptação do prematuro ao meio ambiente ${ }^{(13,14)}$.

Nesta perspectiva, observamos o surgimento de várias propostas de cuidar dos bebês hospitalizados, dentre elas 0 cuidado individualizado de apoio desenvolvimental, que inclui os seguintes elementos: organização do cuidado de forma a reduzir as atividades; agrupar os cuidados; redução de luminosidade e ruídos; cuidados individualizados e envolvimento dos pais nos cuidados ${ }^{(15)}$.

0 cuidado de apoio ao desenvolvimento pode reduzir ou eliminar a manipulação excessiva que os pequenos prematuros sofrem no cotidiano das UCINs, pois a enfermagem passa a planejar seus cuidados de forma individual izada, de acordo com as necessidades dos bebês, substituindo o cuidado rotinizado ${ }^{(16)}$.

Sem desmerecer a importância da dimensão técnica no processo de cuidar, o nosso grande desafio enquanto profissionais cuidadores de bebês é del es cuidar como seres humanos na sua totalidade, com competência tecnocientífica e humana, valorizando a dimensão subjetiva, de forma a resgatar 0 sentido humanitário nas relações interpessoais entre sujeitos, voltados para o acolhimento, autonomia, participação das mães no assistir e com vistas a promoção da saúde e emancipação dos sujeitos.

\section{CONSI DERAÇÕES FINAIS}

Inegável éo valor utilitário da tecnologia nas UCINS, embora muitas vezes precise ser questionado de forma a não tratar a tecnologia como um fim em si mesma. A tecnologia nas UCINs perde seu sentido se não estiver integrada ao processo relacional e, principalmente, se não estiver vinculada aos princípios éticos para a manutenção e valorização da vida.

As U CIN s não podem ser somente um ambiente humanizado nos aspectos da estrutura física e funcional, onde tudo funciona de forma quase perfeita, principal mente sob o aspecto técnico, mas um local em que o lado humano, 0 afeto, a atenção aos familiares e a solidariedade estejam presentes, e os pequenos pacientes sejam tratados como sujeitos e com direito à cidadania.

$N$ ão queremos desmerecer a importância da incorporação tecnológica na assistência à saúde neonatal, mas cabe a cada um de nós, profissionais da saúde, a responsabilidade de não nos af astarmos em nossa práxis da reflexão ética.

A creditamos que há espaço para a tecnologia e o cuidado ético/humanizado. Para tal, há que se reconhecer a humanidade do outro, de quem cuida e do cuidador. Ou seja, é ver a intersubjetividade dos sujeitos, considerar a capacidade de interagir, de manifestar e expressar 
intencionalidade e solidariedade pelo outro, seja ela do cuidador, outro profissional, cliente ou familiares.

Enfim, discutir a questão do cuidado ao recémnascido em U CIN s contribui para reverter o cenário frio e hostil destas unidades, pois nosso propósito maior é a realização de um trabalho que seja impregnado de ética e humanidade.

\section{REFERÊNCIAS}

1. Pessini $L, B$ archifontaine C.P. Problemas atuais de bioética. 5 ed. São Paulo: São Camilo/L oyola; 2000.

2. Segre M. Considerações sobre o princípio de autonomia. M edicina, 1995; 28(1): 10-5.

3. Procianoy RS. Cuidados intensivos neonatais: aspectos éticos. Pediatr Moderna 1996; 32(5): 539-44.

4. Ribeiro CDM. Bioética e Neonatologia. In: Schramm FR, Braz M, organizadores. Bioética e saúde - novos tempos para mulheres e crianças. Rio de Janeiro: Fiocruz, 2005, cap. 10, p.219-36.

5. Brasil. Conselho Nacional dos direitos da Criança e do A dolescente. Resolução $\mathrm{n}-41$ de 13 de outubro de 1995. Dispõe sobre os direitos da criança e do adolescente hospitalizados. Diário Oficial da República Federativa do B rasil, B raślia, p. 16319-16320, 17 out. 1995, Seção I.

6. K letemberg DF, M antovani M F, L acerda M R. Entre a teoria e as práticas do cuidar: que caminho trilhar? Cogitare Enferm 2004; 9(1): 94-99.

7. M inistério da Saúde(B R). Secretaria de Políticas de Saúde. Programa de humanização do pré-natal e nascimento. Brasília; 2000.

8. M inistério da Saúde(BR). Programa Nacional de Humanização da A ssistência Hospitalar. ( PNHAH) B rasília (DF): 2001

9. Gaiva M A M , Scochi CGS. Processo de trabalho em saúde e enfermagem em UTI N eonatal. Rev Latino-A m Enferm 2004; 12(3): 469-76.

10. Gaiva MAM, Gonçalves JPR. 0 cuidado ético. In: VI Congresso B rasileiro de Bioética e I Congresso de Bioetica del M ercosur 2005, Foz do Iguaçu, A nais....Foz do I guaçu: Sociedade Brasileira de Bioética, 2005. p.228.

11. Casate JC, Corrêa AK. Humanização do atendimento em saúde: conhecimento veiculado na literatura brasileira de enfermagem. Rev Latino-A m Enferm 2005; 13(1): 105-11.

12. B off, L Saber cuidar - ética do humano- compaixão pela terra. Petrópolis: Vozes; 1999.

13. Consentino A, M alerba M C. Intervenciones reguladas em el cuidado del recién-nacido prematuro extremo: protocolo de intervenção mínima. Temas de Enfermería A ctualizados 1996; 4(18):22-5.

14. Scochi CGS. A humanização da assistência hospitalar ao bebê prematuro: bases teóricas para o cuidado de enfermagem. [tese]. Ribeirão Preto (SP): Universidade de São Paulo; 2000.

15. Lotas MJ, Walden M. Individualized developmental care for very low-weight infants: a critical review. JOGNN 1996; 25: 681-87.

16. L ockridgeT. Following the learning curve: the evolution of kinder gentler neonatal respiratory technology. JOGNN 1999; 28( 4): 443-55. 